\title{
The efficacy of thymosin alpha 1 for severe sepsis (ETASS): a multicenter, single-blind, randomized and controlled trial
}

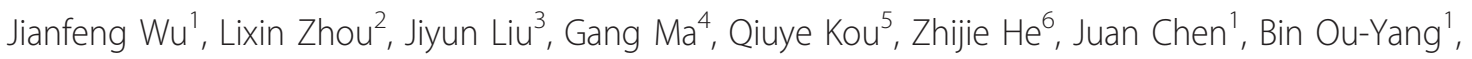
Minying Chen ${ }^{1}$, Yinan $\mathrm{Li}^{2}$, Xiaoqin $\mathrm{Wu}^{3}$, Baochun $\mathrm{Gu}^{4}$, Lei Chen ${ }^{5}$, Zijun Zou ${ }^{6}$, Xinhua Qiang ${ }^{2}$, Yuanyuan Chen ${ }^{3}$, Aihua Lin', Guanrong Zhang ${ }^{7}$ and Xiangdong Guan ${ }^{1 *}$

\begin{abstract}
Introduction: Severe sepsis is associated with a high mortality rate despite implementation of guideline recommendations. Adjunctive treatment may be efficient and require further investigation. In light of the crucial role of immunologic derangement in severe sepsis, thymosin alpha $1(T \alpha 1)$ is considered as a promising beneficial immunomodulatory drug. The trial is to evaluate whether Ta1 improves 28-day all-cause mortality rates and immunofunction in patients with severe sepsis.

Methods: We performed a multicenter randomized controlled trial in six tertiary, teaching hospitals in China between May 12, 2008 and Dec 22, 2010. Eligible patients admitted in ICU with severe sepsis were randomly allocated by a central randomization center to the control group or T 1 group (1:1 ratio). The primary outcome was death from any cause and was assessed 28 days after enrollment. Secondary outcomes included dynamic changes of Sequential Organ Failure Assessment (SOFA) and monocyte human leukocyte antigen-DR (mHLA-DR) on day $0,3,7$ in both groups. All analyses were done on an intention-to-treat basis.

Results: A total of 361 patients were allocated to either the control group $(n=180)$ or $T \alpha 1(n=181)$ group. The mortalities from any cause within 28 days in the Ta1 group and control group were $26.0 \%$ and $35.0 \%$ respectively with a marginal $P$ value (nonstratified analysis, $P=0.062$; log rank, $P=0.049$ ); the relative risk of death in the T 1 group as compared to the control group was 0.74 ( $95 \% \mathrm{Cl} 0.54$ to 1.02). Greater improvement of mHLA-DR was observed in the Ta1 group on day 3 (mean difference in mHLA-DR changes between the two groups was 3.9\%, 95\% Cl 0.2 to $7.6 \%, P=$ 0.037 ) and day 7 (mean difference in mHLA-DR changes between the two groups was 5.8\%, 95\% Cl 1.0 to 10.5\%, $P=0.017)$ than in the control group. No serious drug-related adverse event was recorded.
\end{abstract}

Conclusions: The use of Ta1 therapy in combination with conventional medical therapies may be effective in improving clinical outcomes in a targeted population of severe sepsis.

Trial registration: ClinicalTrials.gov NCT00711620.

\section{Introduction}

Severe sepsis is an important cause of admission to intensive care units (ICUs) throughout the world and is characterized by high mortality in adults [1-3]. Severe sepsis is diagnosed in more than 750,000 people annually in the

\footnotetext{
* Correspondence: guanxiangdong1962@163.com

'Department of Critical Care Medicine, The First Affiliated Hospital of Sun Yat-sen University, 58 Zhongshan Er Road, Guangzhou 510080, Guangdong Province, PR China

Full list of author information is available at the end of the article
}

United States, of whom 215,000 will die [3]. Reported mortality rates of severe sepsis ranged from $28 \%$ to $35.5 \%$ [3-7]. In spite of the adoption of therapeutic bundles based on Surviving Sepsis Campaign (SSC) guidelines, mortality is reported to be about $30 \%$ [4]. The key role of immunologic derangement in the course and the poor outcome has led to an increased interest in immunotherapy $[8,9]$. Thymosin alpha $1(\mathrm{~T} \alpha 1)$ is a naturally occurring thymic peptide first described and characterized by Goldstein et al. [10]. It acts as an endogenous regulator
C Biomed Central

(c) 2013 Wu et al.; licensee BioMed Central Ltd. This is an open access article distributed under the terms of the Creative Commons Attribution License (http://creativecommons.org/licenses/by/2.0), which permits unrestricted use, distribution, and reproduction in any medium, provided the original work is properly cited. 
of both the innate and adaptive immune systems [11]. It is used worldwide for treating diseases associated with immune dysfunction including viral infections such as hepatitis $B$ and $C$, certain cancers, and for vaccine enhancement $[12,13]$. Notably, recent development in immunomodulatory research has indicated the beneficial effect of T $\alpha 1$ treatment in septic patients. However, the results of these studies should be viewed with caution due to their small sample sizes and use of more than one drug as therapeutic intervention [14-16]. This multicenter randomized controlled trial was implemented to determine the efficacy of $\mathrm{T} \alpha 1$ in treating severe sepsis.

\section{Material and methods}

We did a prospective, controlled, single-blinded, multicenter randomized clinical trial, which was conducted in the ICUs of six tertiary, teaching hospitals. The ethics committee of the First Affiliated Hospital of Sun Yat-sen University approved the protocol (200815). Written informed consents were obtained from the patients or next of kin for patients unable to consent. The trial was registered with ClinicalTrials.gov, number NCT00711620.

\section{Patients}

From May 12, 2008 to Dec 22, 2010 patients diagnosed with severe sepsis admitted to ICUs were enrolled in the trial. The criteria for severe sepsis were a modification of those defined by Bernard et al. (see Additional file 1) [7]. Patients were eligible for study inclusion if they had a known or suspected infection based on clinical data at the time of screening and if they had two or more signs of systemic inflammation and sepsis-induced dysfunction of at least one organ or system. Exclusion criteria are summarized in Additional file 2.

\section{Randomization and masking}

To reduce the impact on the results from heterogeneity of severe sepsis and inter-hospital variation in patient sources as much as possible, stratification by investigative center in combination with computer-generated block randomization (block size $=8$ ) according to the sequence of recruitment was employed in the enrollment process. The method of randomization and block size were blinded until the data analysis was finished completely. Clinicians who enrolled the subjects were not involved in data collection. Eligible patients were randomly assigned in a 1:1 ratio in each hospital with four in each block assigned to receive the study drug and the other four to the control group after telephone verification through a randomization center. The allocation sequence was concealed from the researchers. To prevent advance knowledge of treatment assignment and subversion of the allocation sequence, trial entry sheet of the case report form (CRF) was filled out and informed consent was obtained before disclosing the unique participant number and the allocated group; the unique number generated could not be changed and deleted afterward. We used normal saline as placebo. Patients were blinded to the treatment assignments. All statistical analysis was done with masking maintained.

\section{Study drug administration and sepsis management}

In the To1 group, patients received subcutaneous injections of $1.6 \mathrm{mg}$ T $\alpha 1$ (ZADAXIN $^{\mathrm{TM}}$, SciClone Pharmaceuticals, Foster City, CA, USA) twice per day for five consecutive days, then once per day for two consecutive days. Prior to administration, the lyophilized powder is to be reconstituted with $1 \mathrm{ml}$ of the provided diluent (sterile water for injection). After reconstitution, the final concentration of $\mathrm{T} \alpha 1$ is $1.6 \mathrm{mg} / \mathrm{ml}$. In the control group, patients received subcutaneous injections of $1 \mathrm{~mL}$ normal saline twice per day for five consecutive days, then once per day for two consecutive days. According to trial protocol, therapy had to be started within $4 \mathrm{hrs}$ after enrollment.

The treating physicians dictated patient care to current international guidelines [17], including adequate empiric antibiotic therapy based on current recommendations, ventilation regimen (pressure control mode), blood glucose control, resuscitation and hemodynamic support, organ support, sedation or analgesia as needed and adequate nutrition. Empirical antibiotic therapy was considered adequate when at least one effective drug was included in the empirical antibiotic treatment within the first $24 \mathrm{hrs}$ of the admission to the ICU and the optimal dose and the correct route of administration were in accordance with medical standards and in ICU survivors without microbiologically detected microorganism in bloodstream or focus. When the empirical antibiotic therapy had to be changed after microbiological detection of microorganism, it was considered inadequate, whereas in non-survivors without microbiologically detected microorganism in bloodstream or focus it was considered not evaluable [18-20].

\section{Outcomes and data collection}

The primary efficacy end point was death from any cause and was assessed 28 days after the initiation of treatment assignment. Secondary outcomes included dynamic changes of Sequential Organ Failure Assessment (SOFA), $\mathrm{CD}^{4+} / \mathrm{CD}^{8+}$ and monocyte human leukocyte antigen-DR (mHLA-DR) expression measured on day 0 (the day of enrollment), 3 and 7 in both groups. All mHLA-DR measurements were done in the center laboratory of the First Affiliated Hospital of Sun Yat-sen University. $1 \mathrm{ml}$ unprocessed EDTA whole blood was stored on ice at once after drawing and was transferred to the center laboratory as soon as possible to guarantee measurement within 3 hrs after blood drawing. The method of measuring mHLA-DR was mentioned in our 
previous paper [21]. Once patients were enrolled, data including demographic characteristics, microbiological findings (primary infection source and the identified microorganisms) and comorbidities were collected when available. The following clinical parameters were recorded on specific days after enrollment: on day 0 , the severity as assessed by the Acute Physiology and Chronic Health Evaluation II (APACHE II); on day 0, 3, 7, SOFA, hematologic and biochemical findings, results of mHLA-DR, $\mathrm{CD}^{4+} / \mathrm{CD}^{8+}$ tests. The time of the first organ dysfunction was retrospectively estimated according to objective data such as blood gas analysis when the patient was enrolled.

\section{Statistical analysis and sample size}

Based on a previous study [22], a sample size of 334 patients was required to show a reduction in 28-day mortality rate from $50 \%$ to $35 \%$ by T $\alpha 1$ treatment, with a two-sided test $(\alpha$ error $=5 \%$; power $=80 \%)$. Considering a possible drop-out rate of $10 \%$, the trial would need to enroll 368 patients in total. Demographic data, outcome data and other laboratory parameters were summarized by frequency for categorical variables and mean \pm standard deviation (SD) or median with interquartile range (IQR) for continuous variables. Proportions were compared with chi-square test or Fisher's exact test. Continuous variables were tested by means of $t$ test with normal distribution or Wilcoxon rank-sum test with non-normal distribution. The comparison of primary outcome between two groups was performed by means of Cochran-Mantel-Haenszel test, in which patients were stratified on a number of baseline covariates such as mHLA-DR, scores of APACHE and SOFA, surgical and cancer history, sex and age. The corresponding relative risks (RRs) with 95\% confidence intervals (CIs) were computed with logit-adjusted method. Kaplan-Meier estimates without adjustment for baseline covariates were used for survival time analysis, and logrank tests for comparison. To estimate mean changes from baseline in laboratory parameters, linear mixed models for repeated measures were employed, taking into account the clustering of participating centers and repeated measurements within patients. This model included terms for baseline measurement, treatment group, visit, and treatment $\times$ visit interaction. Leastsquares means with $95 \%$ CIs were reported. We also analyzed the efficacy parameters of the study drug in different prespecified subgroups. The heterogeneity of treatment effects among subgroups was assessed with use of interaction tests. Consistent with the intentionto-treat principle, all analyses were based on all available population, consisting of those with a baseline and at least one post-baseline efficacy measurement, neither making any assumption nor imputing the missing data.
All statistical analyses were done with the SAS software (SAS 9.1.3; SAS Institute Inc., Cary, NC, USA). Twosided $P$ values were reported and a $P$ value less than 0.05 was considered as statistically significant.

\section{Results}

\section{Study profile}

Between May 12, 2008 and Dec 22, 2010, 367 eligible patients were randomized (Figure 1 ). In the T $\alpha 1$ group, two patients were excluded: one patient withdrew the consent after being diagnosed with typhus and was transferred to the infectious disease hospital immediately; in the other case, consent was withdrawn before the infusion. In the control group, consents were withdrawn after the enrollment in four cases. A total of 361 randomized patients were followed up for the entire 28-day study period without drop-out. Of 181 patients in T $\alpha 1$ group, 162 patients completed the trial in adherence with the protocol regarding the use of drugs, while the other 19 patients received at least $1.6 \mathrm{mg} \mathrm{T} \alpha 1$ but their treatments did not fully adhere to the protocol because they were transferred out of ICU.

\section{Baseline data}

Both groups had similar characteristics in most demographic and baseline variables (Table 1), although patients in the T $\alpha 1$ group had a longer period between the time of first organ dysfunction observed and the time of enrollment ( 42 hrs vs. 28 hrs, $P=0.003$ ). Nearly $80 \%$ of the patients had at least two dysfunctional organs at the time of enrollment. The pulmonary and cardiovascular systems were the most commonly affected organ systems with an incidence of $94.7 \%$ and $65.7 \%$ respectively. The most common sites of infection were lung and abdomen, with an incidence of 74.5 and $27.4 \%$, with mixed pathogens or gram-negative organisms accounting for the majority of cases. There was no difference in adequate antibiotic treatment (refer to Table 2). Baseline laboratory data were comparable between the two groups and shown in Table 3. Patients in the T $\alpha 1$ group had a lower level of mHLA-DR ( 47.1 vs. $58.0 \%$ in the control group, $P=0.02$ ), but the distribution of each stratum in the two groups was similar.

\section{Study outcomes \\ Primary outcome}

Within 28 days after the enrollment, 47 of 181 patients in the T $\alpha 1$ group (26.0\%) and 63 of 180 patients in the control group (35.0\%) expired. The relative risk of death in the T $\alpha 1$ group as compared to the control group was 0.74 (95\% CI 0.54 to 1.02 ) with a $P$ value of 0.062 in the nonstratified analysis. There was a $9.0 \%$ (95\% CI -0.5 to $18.5 \%)$ absolute reduction in mortality in the T $\alpha 1$ group. Survival time-to-event curves of the two groups are presented in 


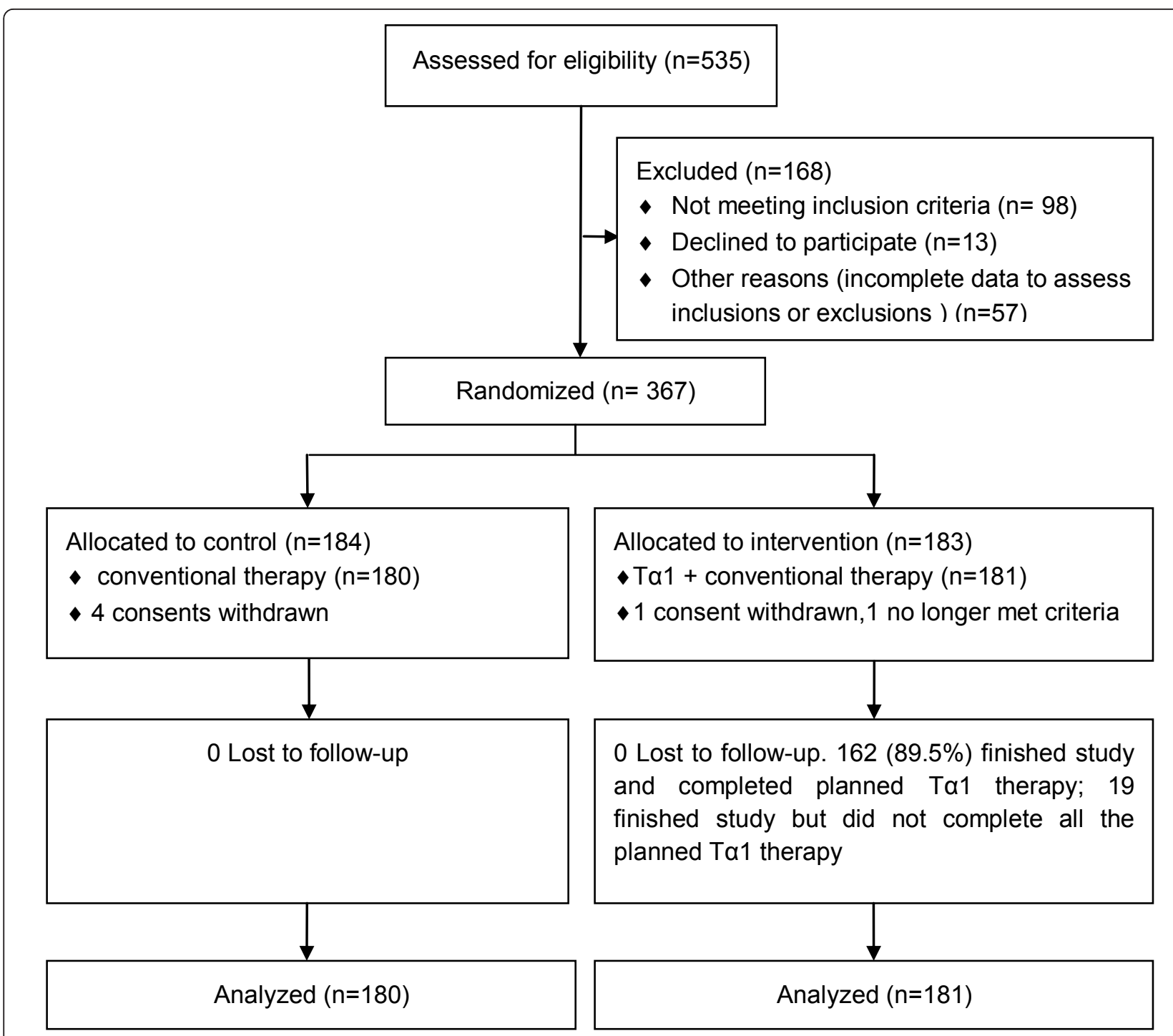

Figure 1 Study profile. $T \alpha 1$, thymosin alpha 1.

Figure 2. Patients in the T $\alpha 1$ group survived longer after enrollment than the control group (log rank, $P=0.049$ ). A total of 52 of 181 patients in the T $\alpha 1$ group (28.7\%) and 71 of 180 patients in the control group (39.4\%) died in hospital. The relative risk of death in hospital in the T $\alpha 1$ group was 0.73 (95\% CI 0.54 to 0.98 ) compared to the control group with a $P$ value of 0.032 . There was no significant difference in ICU mortality, ventilation-free days, ICU-free days, the length of ICU stay and duration of mechanical ventilation between the two groups (Table 4).

\section{Secondary outcomes}

Dynamic changes in SOFA and laboratory measurements are summarized in Table 5. A sustained increase in mHLA-DR values (\% of positive monocytes) was observed in both groups. The mean changes from baseline on day 3 and day 7 were $4.1 \%$ and $11.2 \%$ in the control group, and
$8.0 \%$ and $17.0 \%$ in the T $\alpha 1$ group. Patients in the T $\alpha 1$ group had lower baseline mHLA-DR than those in the control group on day 0 . The average mHLA-DR became comparable with no statistically significant difference between the two groups on day 3 and 7. Greater improvements in mHLA-DR were observed in patients in the T $\alpha 1$ group on day 3 (mean difference in mHLA-DR changes between the two groups was $3.9 \%, 95 \%$ CI 0.2 to $7.6 \%, P=$ 0.037 ) and day 7 (mean difference in mHLA-DR changes between two groups was $5.8 \%, 95 \%$ CI 1.0 to $10.5 \%, P=$ $0.017)$. The average SOFA score changes on day 3 and day 7 were $-1.3(95 \%$ CI -1.7 to $-0.8, P<0.001)$ and $-1.8(95 \%$ CI -2.4 to $-1.3, P<0.001)$ in the control group, and -1.8 (95\% CI -2.3 to $-1.4, P<0.001)$ and -2.5 (95\% CI -3.1 to $-2.0, P<0.001)$ in the T $\alpha 1$ group. The decreasing tendency within 7 days in SOFA score seemed to favor the 
Table 1 Baseline characteristics in both study groups.

\begin{tabular}{|c|c|c|c|}
\hline & Control group & T $\alpha 1$ group & $P$ value \\
\hline$n$ & 180 & 181 & \\
\hline Age (yr) & $66.4 \pm 12.6$ & $64.7 \pm 14.5$ & 0.46 \\
\hline Age group & & & 0.79 \\
\hline$<50 \mathrm{yr}$ & $21(11.7 \%)$ & $24(13.3 \%)$ & \\
\hline $50-60 \mathrm{yr}$ & $39(21.7 \%)$ & $45(24.9 \%)$ & \\
\hline $61-70 \mathrm{yr}$ & $39(21.7 \%)$ & $39(21.6 \%)$ & \\
\hline $71-y r$ & $81(45.0 \%)$ & $73(40.3 \%)$ & \\
\hline Male & $131(72.8 \%)$ & $141(77.9 \%)$ & 0.26 \\
\hline Female & $49(27.2 \%)$ & $40(22.1 \%)$ & \\
\hline BMI & $22.0 \pm 3.0$ & $22.2 \pm 3.1$ & 0.48 \\
\hline \multicolumn{4}{|l|}{ Prior or preexisting conditions } \\
\hline Congestive heart failure & $8(4.4 \%)$ & $5(2.8 \%)$ & 0.39 \\
\hline Hypertension & $79(43.9 \%)$ & $80(44.2 \%)$ & 0.95 \\
\hline Coronary heart disease & $19(10.6 \%)$ & $22(12.2 \%)$ & 0.63 \\
\hline Liver disease & $10(5.6 \%)$ & $9(5.0 \%)$ & 0.80 \\
\hline COPD & $28(15.6 \%)$ & $29(16.0 \%)$ & 0.90 \\
\hline Nervous system diseases & $33(18.3 \%)$ & $32(17.7 \%)$ & 0.87 \\
\hline Diabetes & $34(18.9 \%)$ & $40(22.1 \%)$ & 0.45 \\
\hline Recent trauma & $8(4.4 \%)$ & $8(4.4 \%)$ & 0.99 \\
\hline Cancer & $55(30.6 \%)$ & $60(33.2 \%)$ & 0.60 \\
\hline Recent surgical history & & & 0.47 \\
\hline No history of surgery & $103(57.2 \%)$ & $92(50.8 \%)$ & \\
\hline Elective surgery & $41(22.8 \%)$ & $46(25.4 \%)$ & \\
\hline Emergency surgery & $36(20.0 \%)$ & $43(23.8 \%)$ & \\
\hline \multicolumn{4}{|l|}{ Other indicators of disease severity } \\
\hline Mechanical ventilation & $143(79.4 \%)$ & $146(80.7 \%)$ & 0.77 \\
\hline Shock & $74(41.1 \%)$ & $64(35.4 \%)$ & 0.26 \\
\hline Use of any vasopressor or dobutamine & $72(40.0 \%)$ & $71(39.2 \%)$ & 0.88 \\
\hline Low-dose corticoid & $18(10.0 \%)$ & $20(11.1 \%)$ & 0.75 \\
\hline Blood transfusion & $54(30.0 \%)$ & $64(35.4 \%)$ & 0.28 \\
\hline \multicolumn{4}{|l|}{ Baseline acute organ dysfunctions } \\
\hline Pulmonary & $170(94.4 \%)$ & $172(95.0 \%)$ & 0.80 \\
\hline Renal & $48(26.7 \%)$ & $53(29.3 \%)$ & 0.58 \\
\hline Cardiovascular & $113(62.8 \%)$ & $124(68.5 \%)$ & 0.25 \\
\hline Hematologic & $69(38.3 \%)$ & $67(37.0 \%)$ & 0.80 \\
\hline Hepatic & $39(21.7 \%)$ & $27(14.9 \%)$ & 0.10 \\
\hline Number of acute organ dysfunction & & & 0.97 \\
\hline 1 & $32(17.8 \%)$ & $29(16.0 \%)$ & \\
\hline 2 & $75(41.7 \%)$ & $77(42.5 \%)$ & \\
\hline 3 & $45(25.0 \%)$ & $48(26.5 \%)$ & \\
\hline 4 & $18(10.0 \%)$ & $19(10.5 \%)$ & \\
\hline 5 & $10(5.6 \%)$ & $8(4.4 \%)$ & \\
\hline APACHE II score & $21.6 \pm 7.7$ & $22.3 \pm 6.7$ & 0.35 \\
\hline SOFA score & $7.7 \pm 3.9$ & $7.9 \pm 3.6$ & 0.65 \\
\hline Respiratory system & $2.6 \pm 1.0$ & $2.7 \pm 0.9$ & 0.22 \\
\hline Coagulation & $0.8 \pm 1.1$ & $1.0 \pm 1.2$ & 0.17 \\
\hline Cardiovascular system & $1.4 \pm 1.6$ & $1.2 \pm 1.5$ & 0.40 \\
\hline Liver & $0.6 \pm 0.9$ & $0.5 \pm 0.8$ & 0.38 \\
\hline Nervous system & $1.3 \pm 1.4$ & $1.4 \pm 1.4$ & 0.69 \\
\hline Renal system & $1.0 \pm 1.3$ & $1.0 \pm 1.4$ & 0.85 \\
\hline Time from first organ dysfunction to enrollment (hr) median(IQR) & $28.0(15.0-48.0)$ & $42.0(24.0-72.0)$ & 0.003 \\
\hline
\end{tabular}

APACHE II, Acute Physiology and Chronic Health Evaluation II; BMI, body mass index; COPD, chronic obstructive pulmonary disease; IQR, interquartile range; SOFA, Sequential Organ Failure Assessment; T 1, thymosin alpha 1; yr, year. 
Table 2 Sites, causes of infection and adequate antibiotic treatment in patients with severe sepsis.

\begin{tabular}{|c|c|c|c|}
\hline & $\begin{array}{l}\text { Control } \\
\text { group } \\
(n=180)\end{array}$ & $\begin{array}{l}\text { T } \alpha 1 \\
\text { group } \\
(n=181)\end{array}$ & $\begin{array}{l}P \\
\text { value }\end{array}$ \\
\hline \multicolumn{4}{|l|}{ Sites of infection* } \\
\hline Lung & $133(73.9 \%)$ & $\begin{array}{l}136 \\
(75.1 \%)\end{array}$ & 0.79 \\
\hline Abdomen & $48(26.7 \%)$ & $51(28.2 \%)$ & 0.75 \\
\hline Urinary tract & $5(2.8 \%)$ & $2(1.1 \%)$ & 0.28 \\
\hline Positive blood culture & $10(5.6 \%)$ & $11(6.1 \%)$ & 0.83 \\
\hline Other $^{\dagger}$ & $18(10.0 \%)$ & $16(8.8 \%)$ & 0.71 \\
\hline Results of pathogens & & & 0.99 \\
\hline Pure gram-negative & 47 (26.1\%) & $51(28.2 \%)$ & \\
\hline Pure gram-positive & $15(8.3 \%)$ & $14(7.7 \%)$ & \\
\hline Pure fungus & $22(12.2 \%)$ & $21(11.6 \%)$ & \\
\hline Mixed & $57(31.7 \%)$ & $56(30.9 \%)$ & \\
\hline Culture negative & $39(21.7 \%)$ & $39(21.6 \%)$ & \\
\hline \multicolumn{4}{|l|}{ Types of organisms } \\
\hline \multicolumn{4}{|l|}{ Gram-positive } \\
\hline Staphylococcus aureus & 7 (3.9\%) & $9(5.0 \%)$ & 0.62 \\
\hline $\begin{array}{l}\text { Other staphylococcus } \\
\text { species }\end{array}$ & $9(5.0 \%)$ & $12(6.6 \%)$ & 0.51 \\
\hline Enterococcus species & $22(12.2 \%)$ & $23(12.7 \%)$ & 0.89 \\
\hline Other gram-positive & $18(10.0 \%)$ & $14(7.7 \%)$ & 0.45 \\
\hline \multicolumn{4}{|l|}{ Gram-negative } \\
\hline Klebsiella species & $18(10.0 \%)$ & $22(12.2 \%)$ & 0.51 \\
\hline Escherichia coli & $25(13.9 \%)$ & $23(12.7 \%)$ & 0.74 \\
\hline Pseudomonas species & $32(17.8 \%)$ & $32(17.7 \%)$ & 0.98 \\
\hline Acinetobacter & $8(4.4 \%)$ & $15(8.3 \%)$ & 0.14 \\
\hline Enterobacter species & $4(2.2 \%)$ & $4(2.2 \%)$ & 1.00 \\
\hline Other gram-negative & $14(7.8 \%)$ & $16(8.8 \%)$ & 0.71 \\
\hline \multicolumn{4}{|l|}{ Fungus } \\
\hline Candida albicans & $43(23.9 \%)$ & $38(21.0 \%)$ & 0.51 \\
\hline Other candida species & $20(11.1 \%)$ & $15(8.3 \%)$ & 0.36 \\
\hline Mould & $1(0.6 \%)$ & $4(2.2 \%)$ & 0.37 \\
\hline Other fungus & $6(3.3 \%)$ & $6(3.3 \%)$ & 0.99 \\
\hline Empirical antibiotic therapy & & & 0.903 \\
\hline Adequate & $136(75.6 \%)$ & $\begin{array}{l}133 \\
(73.5 \%)\end{array}$ & \\
\hline Inadequate & $34(18.9 \%)$ & 37 (20.4\%) & \\
\hline Not evaluable & $10(5.6 \%)$ & $11(6.1 \%)$ & \\
\hline
\end{tabular}

*Patients may have had more than one site of infection; tother sites of infection included skin, central nervous system, bones and joints; $\neq$ patients may have had more than one organism cultured. To1, thymosin alpha 1.

T $\alpha 1$ group but with no significant difference in changes between the two groups. The ratio of $\mathrm{CD}^{4+} / \mathrm{CD}^{8+}$ remained unchanged during the 7 days in both groups.

\section{Subgroup analysis}

Mortality rates among prespecified subgroups of patients are shown in Figure 3. Prespecified analyses of the primary end point, where patients were stratified according to APACHE II score, SOFA score, mHLA-DR level, history of surgery or cancer, sex and age, showed that T $\alpha 1$ tended
Table 3 Baseline levels of laboratory values.

\begin{tabular}{|c|c|c|c|}
\hline & Control group & 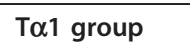 & $P$ value \\
\hline \multicolumn{4}{|l|}{ mHLA-DR (\%) } \\
\hline Median (IQR) & $58.0(33.9-83.0)$ & $47.1(26.4-71.1)$ & 0.02 \\
\hline mHLA-DR group & & & 0.16 \\
\hline$<30 \%(\mathrm{n}, \%)$ & $36(20.3 \%)$ & $50(27.6 \%)$ & \\
\hline$\geq 30-<45 \%(n, \%)$ & $29(16.4 \%)$ & $32(17.7 \%)$ & \\
\hline$\geq 45-<85 \%(n, \%)$ & $70(39.6 \%)$ & $71(39.2 \%)$ & \\
\hline$\geq 85 \%(n, \%)$ & 42 (23.7\%) & $28(15.5 \%)$ & \\
\hline \multicolumn{4}{|l|}{$\mathrm{CD}^{4+} / \mathrm{CD}^{8+}$} \\
\hline Median (IQR) & $1.95(1.18-3.30)$ & $1.87(1.16-3.22)$ & 0.64 \\
\hline \multicolumn{4}{|l|}{ WBC $\left({ }^{*} 10^{9}\right)$} \\
\hline Median level & $14.3(10.1-17.9)$ & $14.4(9.4-19.3)$ & 0.78 \\
\hline \multicolumn{4}{|l|}{ Neutrophil (\%WBC) } \\
\hline Median (IQR) & $85.1(80.2-90.7)$ & $86.5(80.8-91.0)$ & 0.48 \\
\hline \multicolumn{4}{|l|}{ Lymphocyte (\%WBC) } \\
\hline Median (IQR) & $9.5(6.0-15.3)$ & $8.9(5.0-14.1)$ & 0.23 \\
\hline \multicolumn{4}{|l|}{ Monocyte (\%) } \\
\hline Median (IQR) & $4.80(3.30-7.30)$ & $4.95(2.80-7.30)$ & 0.66 \\
\hline \multicolumn{4}{|l|}{ Lactate (mmol/L) } \\
\hline Median (IQR) & $2.1(1.4-3.4)$ & $2.1(1.3-3.1)$ & 0.86 \\
\hline
\end{tabular}

$\mathrm{CD}$, cluster of differentiation; IQR, interquartile range; mHLA-DR, monocyte human leukocyte antigen-DR; WBC, white blood cell; T $\alpha 1$, thymosin alpha 1.

to improve outcome but without statistical significance. In a subgroup analysis of patients with cancer, the relative risk of death of the T $\alpha 1$ group when compared to the control group was 0.46 (95\% CI 0.25 to $0.86, P=0.01$ ); on the other hand, in non-cancerous patients, the relative risk of death of the T $\alpha 1$ group was $0.91(P=0.07$ by the test of interaction).

\section{Adverse events}

Safety and tolerability assessment of T $\alpha 1$ (see Additional file 3) was based on the comparison of all available information obtained from the two groups with respect to detected outliers in laboratory safety data, drugrelated serious adverse events (assessed by the investigator) and deterioration of organ and system function (assessed by the individual SOFA component scoring for respiratory, cardiovascular, hepatic, coagulation, renal and nervous systems that arose during the treatment).

In this study, no Ta1-related severe adverse event (SAE) was reported and no treatment was discontinued due to intolerance or adverse events. There were no statistically significant differences between the control and $\mathrm{T} \alpha 1$ group with regard to the frequency of outlying laboratory values and all-cause organ or system impairment (refer to Table 6).

\section{Discussion}

Immune system dysregulation plays a significant role in the course of sepsis. Previously, it was believed that the exaggerated pro-inflammatory response and its associated 


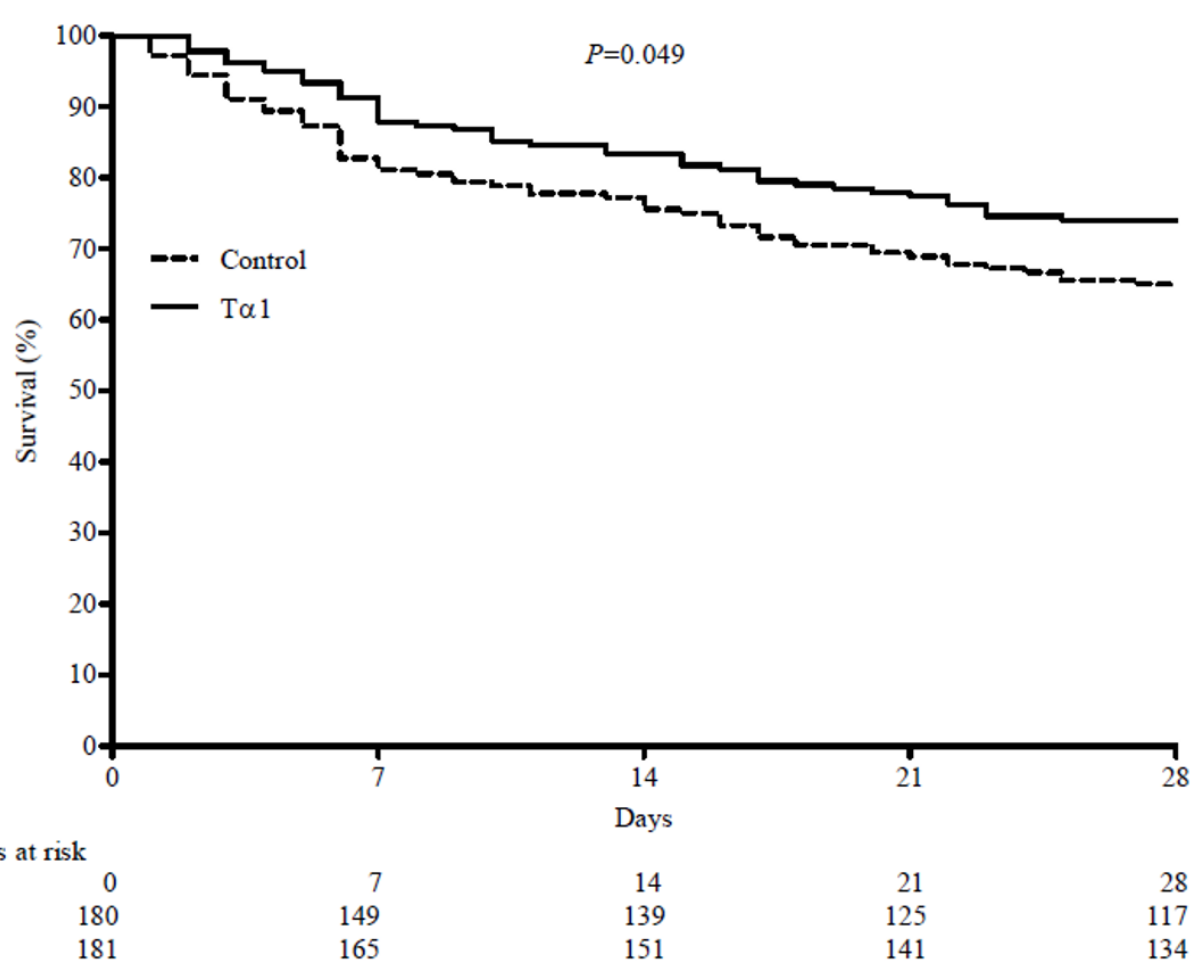

Figure $\mathbf{2}$ Kaplan-Meier estimate of the probability of $\mathbf{2 8}$-day survival. $T \alpha 1$, thymosin alpha 1.

inflammation-induced organ injury were the major factors leading to deaths in sepsis. However, recent studies indicate that heterogeneity exists in septic patients' immune response, with some appearing immunostimulated, whereas in others appearing suppressed [23]. Although both pro-inflammatory and

Table 4 Primary outcome and prognosis.

\begin{tabular}{|c|c|c|c|}
\hline & $\begin{array}{l}\text { Control group } \\
(n=180)\end{array}$ & $\begin{array}{l}T \alpha 1 \\
(n=181)\end{array}$ & $\begin{array}{l}P \\
\text { value }\end{array}$ \\
\hline 28-day mortality & $63(35.0 \%)$ & $47(26.0 \%)$ & 0.062 \\
\hline In-hospital mortality & 71 (39.4\%) & $52(28.7 \%)$ & 0.032 \\
\hline In-ICU mortality & $48(26.7 \%)$ & $35(19.3 \%)$ & 0.098 \\
\hline \multicolumn{4}{|l|}{$\begin{array}{l}\text { Duration of } \\
\text { ventilation }\end{array}$} \\
\hline Median (IQR) & $6.0(2.0-14.0)$ & $7.0(3.0-13.0)$ & 0.742 \\
\hline \multicolumn{4}{|l|}{ ICU stay } \\
\hline Median (IQR) & $10.5(5.0-20.5)$ & $11.0(7.0-20.0)$ & 0.254 \\
\hline \multicolumn{4}{|c|}{ Ventilation-free days* } \\
\hline Median (95\% Cl) & $13.0(7.0-18.0)$ & $\begin{array}{l}18.0(15.0- \\
21.0)\end{array}$ & 0.077 \\
\hline \multicolumn{4}{|l|}{ ICU-free days* } \\
\hline Median (95\% Cl) & $5.0(0.3-10.7)$ & $10.0(6.8-15.0)$ & 0.235 \\
\hline
\end{tabular}

'Free days' were calculated as the number of days that the patient was alive and free of given measure (ventilator use and ICU stay) during the 28-day study period. $\mathrm{Cl}$, confidence interval; $\mathrm{IQR}$, interquartile range; $\mathrm{T} \alpha 1$, thymosin alpha 1. anti-inflammatory drugs have been evaluated, few have yet been found to significantly reduce the mortality [24-26]. T $\alpha 1$ is thought to have immunomodulating effects primarily affecting the augmentation of $\mathrm{T}$-cell function $[27,28]$. T $\alpha 1$ has also shown actions beyond its effect on $\mathrm{T}$ lymphocytes by acting as an endogenous regulator of both the innate and adaptive immune systems $[11,29]$. $T \alpha 1$ plays a unique role in balancing pro- and anti-inflammatory cytokine production through the involvement of distinct Toll-like receptors (TLRs) acting on different dendritic cells (DC) subsets and involving the MyD88-dependent signaling pathway. T $\alpha 1$ can increase IL-12, IL-2, IFN- $\alpha$ and IFN- $\gamma$ secretion to present antimicrobial effect and increase IL-10 and percentage of regulatory T cells (Tregs) to control inflammation [11,30-32]. Therefore, theoretically, T $\alpha 1$ may be an appropriate immunoregulator for treating severe sepsis that is characterized by the large heterogeneity in immune function.

Our data suggested that the administration of $\mathrm{T} \alpha 1$ reduced 28-day mortality from any cause in patients with clinically diagnosed severe sepsis by $9.0 \%$, with a marginal $P$ value $(P=0.062$ in the nonstratified analysis; log rank, $P=0.049)$ and decreased in-hospital mortality $(P=0.032)$. Our study was prospectively set up to detect an absolute $15 \%$ mortality reduction from an expected $50 \%$ as indicated in our previous trial and another epidemiology research 
Table 5 Dynamic changes of SOFA and laboratory measurements.

\begin{tabular}{|c|c|c|c|}
\hline Measures & $\begin{array}{l}\text { Control } \\
\text { group }\end{array}$ & 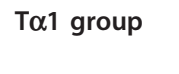 & $\begin{array}{l}\text { Between groups } \\
\text { difference }\end{array}$ \\
\hline & $\begin{array}{l}\text { Mean }(95 \% \\
\mathrm{Cl})\end{array}$ & $\begin{array}{l}\text { Mean }(95 \% \\
\mathrm{Cl})\end{array}$ & \\
\hline \multicolumn{4}{|l|}{ SOFA score } \\
\hline Day 0 & $7.7(6.8-8.5)$ & $7.9(7.0-8.7)$ & \\
\hline Day 3 & $6.4(5.6-7.2)$ & $6.1(5.2-6.9)$ & \\
\hline Day 7 & $5.9(5.0-6.7)$ & $5.3(4.5-6.2)$ & \\
\hline $\begin{array}{l}\triangle \text { Day } \\
3^{*}\end{array}$ & $\begin{array}{l}-1.3(-1.7-0.8) \\
a\end{array}$ & $-1.8(-2.3-1.4)^{a}$ & $-0.5(-1.2-0.1)$ \\
\hline $\begin{array}{l}\Delta \text { Day } \\
7^{*}\end{array}$ & $\begin{array}{l}-1.8(-2.4-1.3) \\
a\end{array}$ & $-2.5(-3.1-2.0)^{\mathrm{a}}$ & $-0.7(-1.5-0)$ \\
\hline \multicolumn{4}{|l|}{$\begin{array}{l}\text { mHLA-DR } \\
(\%)\end{array}$} \\
\hline Day 0 & $\begin{array}{l}58.2(38.8- \\
77.6)\end{array}$ & $\begin{array}{l}51.8(32.5- \\
71.2)\end{array}$ & \\
\hline Day 3 & $\begin{array}{l}62.2(42.8- \\
81.6)\end{array}$ & $\begin{array}{l}59.8(40.4- \\
79.2)\end{array}$ & \\
\hline Day 7 & $\begin{array}{l}69.4(50.0- \\
88.8)\end{array}$ & $\begin{array}{l}68.9(49.5- \\
88.2)\end{array}$ & \\
\hline $\begin{array}{l}\triangle \text { Day } \\
3^{*}\end{array}$ & $4.1(1.4-6.7)^{b}$ & $8.0(5.4-10.5)^{b}$ & $3.9(0.2-7.6)^{a}$ \\
\hline $\begin{array}{l}\Delta \text { Day } \\
7^{*}\end{array}$ & $\begin{array}{l}11.2(7.8-14.7) \\
b\end{array}$ & $\begin{array}{l}17.0(13.7- \\
20.3)^{\mathrm{b}}\end{array}$ & $5.8(1.0-10.5)^{\mathrm{a}}$ \\
\hline \multicolumn{4}{|l|}{$\mathrm{CD}^{4+} / \mathrm{CD}^{8+}$} \\
\hline Day 0 & $2.4(2.0-2.9)$ & $2.5(2.0-2.9)$ & \\
\hline Day 3 & $2.7(2.2-3.1)$ & $2.7(2.3-3.2)$ & \\
\hline Day 7 & $2.4(2.0-2.9)$ & $2.5(2.1-3.0)$ & \\
\hline $\begin{array}{l}\triangle \text { Day } \\
3^{*}\end{array}$ & $0.2(0-0.5)$ & $0.3(0-0.5)^{\mathrm{a}}$ & $0(-0.3-0.4)$ \\
\hline $\begin{array}{l}\triangle \text { Day } \\
7^{*}\end{array}$ & $0(-0.3-0.3)$ & $0.1(-0.2-0.4)$ & $0.1(-0.3-0.5)$ \\
\hline
\end{tabular}

* $\Delta$ Day 3 and $\Delta$ Day 7 were defined as the value changes on day 3 and day 7 compared with that on day $0 .{ }^{\mathrm{a}} P<0.05 ;{ }^{\mathrm{b}} P<0.01$. CD, cluster of differentiation; $\mathrm{Cl}$, confidence interval; mHLA-DR, monocyte human leukocyte antigen-DR; SOFA, Sequential Organ Failure Assessment; $T \alpha 1$, thymosin alpha 1.

about severe sepsis in China [22,33]. Mortality and drug effect size were not consistent with our expectation, which might lead to the marginal $P$ value in the comparison of 28-day survival rate between two groups. In contrast to our results, previous trials in adults indicated that Ta1 significantly reduced mortality by $13.1 \%$ to $18 \%$ as compared to the control group [14-16]. The following reasons may explain this discrepancy in different trials. First, heterogeneity in patient populations and different therapeutic approaches could have influenced the outcomes; second, previous trials did not report the allocation concealment, which could have an unexpected impact on results. Schulz et al. indicated that the odds ratios were exaggerated by $41 \%$ for inadequately concealed trials and by $30 \%$ for unclearly concealed trials [34]. Third, those studies used more than one drug as therapeutic intervention and made it difficult to attribute the beneficial effects observed to each agent.
The most frequently assessed biomarker for evaluating immune function of severe sepsis is mHLA-DR. There seems to be a general consensus that diminished mHLADR is a reliable marker for the development of immunodysfuction in severe sepsis patients [35,36]. Recent studies indicate that the dynamic change of mHLA-DR over time was a better predictor of mortality and mHLA-DR recovery was associated with a better prognosis $[21,37,38]$. In the present trial, a greater improvement of mHLA-DR was observed in the T $\alpha 1$ group on day 3 and day 7 than in the control group, which suggests that $\mathrm{T} \alpha 1$ may improve immune function in severe sepsis. The ratio of $\mathrm{CD}^{4+} / \mathrm{CD}^{8+}$ is another parameter to evaluate immunological status in sepsis. Decreased $\mathrm{CD} 4^{+} / \mathrm{CD}^{+}$ratio was related to the development of severe sepsis and multiple organ failure (MOF) in trauma patients [39]. Some studies showed that thymosin alpha 1 can increase $\mathrm{CD} 4^{+} / \mathrm{CD}^{+}$ratio $[40,41]$. On the other side, one research study has indicated that mHLA-DR, not $\mathrm{CD}^{4+}, \mathrm{CD}^{8+}$ or ratio of $\mathrm{CD}^{4+} / \mathrm{CD}^{8+}$, can predict the prognosis of severe sepsis [42]. In our research, we did not find statistically significant difference in the $\mathrm{CD}^{+} / \mathrm{CD}^{+}$ratio between the two groups. The decreasing tendency within 7 days in SOFA score seemed to favor the $\mathrm{T} \alpha 1$ group but with no significant difference in changes between the two groups. However, considering the fact that we observed the changes of these indices for only 7 days, there could have been some difference between the two groups if the observation had been extended to 14 or 28 days.

The median time from the first organ dysfunction detected to enrollment was more than 24 hrs in both groups, but longer in the T $\alpha 1$ group. We adopted a retrospective method to determine the time window between the onset of the first organ dysfunction detected and study enrollment according to objective data (such as blood gas analysis), many of which were obtained before transferring the severe sepsis patients to the ICU [7]. However, those patients without indicative objective data could also have suffered from severe sepsis and the delay in laboratory tests could substantially underestimate the time after onset. In other words, the time after onset determined by laboratory tests in non-ICU departments was out of our control and subject to errors, especially when the estimation was based on hours instead of days. The precise time window between onset of the first organ dysfunction and enrollment could exceed the recorded time and could possibly be balanced between the two groups. The better way of enrolling severe sepsis patients in immunotherapy research may be through mHLA-DR value, which has been proved to be a good predictor to evaluate patients' immune status and a good parameter for individualized goal-directed therapy [43].

Reductions in the relative risk of death were observed in all subgroups including those stratified according to 


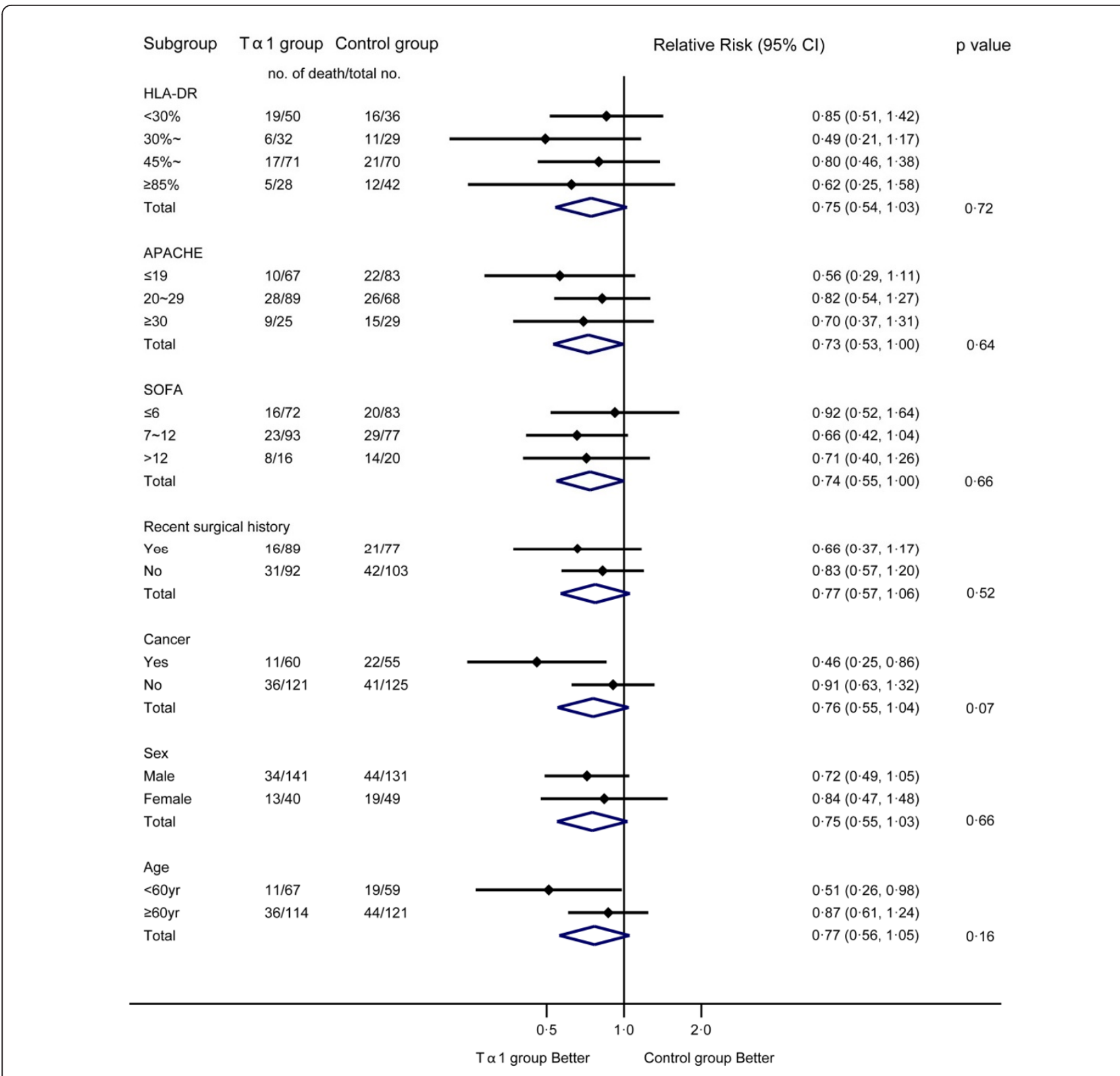

Figure 3 Analysis of the rates and risks of death from any cause within $\mathbf{2 8}$ days in prespecified subgroups. APACHE, Acute Physiology and Chronic Health Evaluation; CI, confidence interval; HLA-DR, human leukocyte antigen-DR; SOFA, Sequential Organ Failure Assessment; T 1 , thymosin alpha 1.

age, sex, APACHE II score, SOFA score and levels of mHLA-DR, but without statistical significance. The aim of analyzing different prespecified subgroups in our research was to prepare for our future research in targeted specific groups of severe sepsis patients who might benefit from the T $\alpha 1$ treatment since it is unlikely that thymosin alpha 1 is equally beneficial to all patients in view of the significant heterogeneity in severe sepsis patients. The results of subgroup analysis in our research were inconclusive and whether T $\alpha 1$ is more effective in specific groups of patients with severe sepsis should be explored in trials with a larger sample size.

Types of pathogen and empirical antibiotic therapy are very important factors that affect the outcome of severe sepsis. In our study, there was no difference between groups in these perspectives. It is noted that the origins of microorganisms are substantially diverse in different areas and even in different hospitals in the same area. So is empirical therapy. In the present study, there was a high isolation rate of gram-negative bacteria (pseudomonas, 
Table 6 Frequency of patients with outlying values of laboratory safety assays and all-cause organ and system impairment.

\begin{tabular}{|c|c|c|c|}
\hline & $\begin{array}{l}\text { Control group } \\
\text { No. }(\%)(n=180)\end{array}$ & $\begin{array}{l}\text { Ta1 group } \\
\text { No. }(\%)(n=181)\end{array}$ & $P$ value \\
\hline \multicolumn{4}{|l|}{ Laboratory safety assays } \\
\hline $\mathrm{ALT}(\mathrm{U} / \mathrm{L})$ & $43(23.9)$ & $38(21.0)$ & 0.51 \\
\hline AST (U/L) & $44(24.4)$ & $43(23.8)$ & 0.88 \\
\hline Hypoglycemia & $9(5.0)$ & $8(4.4)$ & 0.79 \\
\hline Hemoglobin (g/L) & $23(12.8)$ & $27(14.9)$ & 0.56 \\
\hline Platelets $\left(10^{3} / \mathrm{mm}^{3}\right)$ & $77(42.8)$ & $67(37.0)$ & 0.26 \\
\hline Creatinine $(\mathrm{mmol} / \mathrm{L})$ & $12(6.7)$ & $18(9.9)$ & 0.26 \\
\hline \multicolumn{4}{|l|}{ SOFA component scores* } \\
\hline Respiratory system & $27(15.0)$ & $24(13.3)$ & 0.64 \\
\hline Coagulation system & $52(28.9)$ & $48(26.5)$ & 0.62 \\
\hline Cardiovascular system & $21(11.7)$ & $28(15.5)$ & 0.29 \\
\hline Hepatic system & $25(13.9)$ & $21(11.6)$ & 0.51 \\
\hline Nervous system & $22(12.2)$ & $14(7.7)$ & 0.15 \\
\hline Renal system & 19 (10.6) & $26(14.4)$ & 0.27 \\
\hline
\end{tabular}

*Organ and system impairment based on the deterioration of SOFA component scores during the treatment. ALT, alanine aminotransferase; AST, aspartate aminotransferase; SOFA, Sequential Organ Failure Assessment; T 1 , thymosin alpha 1.

acinetobacter) compared with some other epidemiology study of infection in ICU [44]. In fact, the relatively higher incidence of pseudomonas and acinetobacter infections is not unusual in China [33] so that the adequate empirical therapy is adjusted accordingly.

Thymosin alpha 1 has been shown to be a safe and well-tolerated agent in other studies [12,13]. Serious adverse events were not observed in our trial. Outlying laboratory values and all-cause organ and system impairment were similar in both groups. However, subjective sensations such as irritation or burning, general or gastrointestinal disorders were difficult to assess due to the severity of disease, sedation or analgesia in severe sepsis patients.

In our study, several factors limit the extent to which the results can be generalized. First, the study population was heterogeneous with respect to clinical features. Although over 80 baseline characteristics were comparable between the two groups, difference in mHLA-DR expression was present and was probably due to the heterogeneity in patients and the relatively small size of samples. In fact, unbalanced baseline characters between groups were not rare in severe sepsis trials even with large samples $[45,46]$. In our study, to assess whether outcomes differed by treatment groups, linear mixed models for longitudinal data were fit with adjustment for the baseline value. This method has been widely used in multicenter research $[47,48]$. Second, considering the heterogeneity of severe sepsis, some patient groups could benefit more from the intervention than other septic patients. The future individualized and goal-directed $T \alpha 1$ treatment of severe sepsis should be implemented in targeted specific groups of patients. One of the biomarkers that can be used to stratify patients according to their immune status is mHLA-DR. Meisel et al. reported that mHLA-DR level was associated with immunosuppression status in sepsis patients who benefited from the granulocyte-macrophage colony-stimulating factor (GM-CSF) treatment [43]. We will try to adopt mHLA-DR target immunosuppression patients in future study. Third, since a considerable proportion of patients were transferred out of ICU within one week, which makes it difficult to guarantee that the complete laboratory and follow-up data could be obtained, we only collected laboratory data within 7 days and followed up the survival status for 28 days. A more extensive laboratory data collection and extended follow-up period could possibly provide more significant information. Fourth, there are few biomarkers to evaluate the immunological derangement. In the present trial, we adopted the widely used mHLA-DR. Fifth, it is not known from our trial that whether the extension of the treatment to more than 7 days or the increase of dose could generate a significant improvement in the outcomes of severe sepsis patients. Sixth, we did not adopt the double-blind method because no identicalappearing placebo was available and only the patients and the statistician were blinded. To minimize the potential bias, randomization and adequate allocation concealment were meticulous in the trial [34] and the primary and second end points were objective rather than subjective.

Given these limitations, the present research is a preliminary exploration on the efficacy of thymosin alpha 1 in severe sepsis and further double-blinded studies are needed to explore the use of $T \alpha 1$ regarding patient selection, dosage and the course of treatment. 


\section{Conclusions}

This RCT demonstrates that thymosin alpha 1 therapy in combination with conventional medical therapy may be effective in improving clinical outcomes in a targeted population of severe sepsis. Larger multicenter studies are indicated to confirm these findings.

\section{Key messages}

- In light of the crucial role of immunologic derangement in severe sepsis, immunotherapy may be an important adjunctive treatment.

- This study demonstrates that immunodulation with thymosin alpha 1 may effectively improve outcomes of patients with severe sepsis. A beneficial impact on the immunofunction of patients with severe sepsis was also observed. Further researches are needed to confirm these findings.

\section{Additional material}

Additional file 1: Study inclusion criteria. The detailed criteria to be fulfilled for study inclusion.

Additional file 2: Study exclusion criteria. Patients who met the criteria were excluded.

Additional file 3: Safety and tolerability assessment of thymosin alpha 1. Safety and tolerability assessment of thymosin alpha 1 was based on the comparison of all available information obtained from the two groups with respect to detected outliers in laboratory safety data, drug-related serious adverse events and deterioration of organ and system function.

\section{Abbreviations}

ALT: alanine aminotransferase; APACHE II: Acute Physiology and Chronic Health Evaluation II; AST: aspartate aminotransferase; BMI: body mass index; CD: cluster of differentiation; Cl: confidence interval; ICU: Intensive Care Unit; IFN: interferon; IL: interleukin; IQR: interquartile range; $P$ : $P$ value; $\mathrm{mHLA}-\mathrm{DR}$ : monocyte human leukocyte antigen-DR; OR: odds ratio; SIRS: systemic inflammatory response syndrome; SOFA: Sequential Organ Failure Assessment; Ta1: thymosin alpha 1; WBC: white blood cell.

\section{Authors' contributions}

$J W, X G$ designed the research; JC, BO, MC, LZ, YL, XQ, JL, XW, YC, GM, BG, $\mathrm{QK}, \mathrm{LC}, \mathrm{ZH}, \mathrm{ZZ}$ performed the research and collected data; $\mathrm{AL}, \mathrm{GZ}$ analyzed the data; JW wrote the manuscript. All authors read and approved the final manuscript.

\section{Competing interests}

The authors declare that they have no competing interests.

\section{Acknowledgements}

We would like to thank all of the doctors, nurses, technicians, and patients involved at the six participating centers for their dedication to the study. We also thank Yun Zhong, Michael Quinte and Ström Christer for their kind help with the manuscript. The authors gratefully thank Qing-Yu Kong, Department of Nephrology, Sun Yat-sen University, for excellent technical assistance.

This study was funded by Sun Yat-sen University Clinical Research Program 5010; the Office of Medical Science of Sun Yat-sen University supervised the research including the study design, protocol, ethics issues, data collection, case report forms and drug side effects. This work was in part supported by
Guangdong Natural Science Foundation (10451008901006286) and Guangdong Medical Scientific Research Foundation (B2010074).

\section{Author details}

${ }^{1}$ Department of Critical Care Medicine, The First Affiliated Hospital of Sun Yat-sen University, 58 Zhongshan Er Road, Guangzhou 510080, Guangdong Province, PR China. ${ }^{2}$ Department of Critical Care Medicine, Foshan First Municipal People's Hospital, 81 Lingnan North Road, Foshan 528000, Guangdong Province, PR China. ${ }^{3}$ Department of Critical Care Medicine, Guangzhou First Municipal People's Hospital, 1 PanFu Road, Guangzhou 510180, Guangdong Province, PR China. ${ }^{4}$ Department of Critical Care Medicine, Sun Yat-sen University Cancer Center, 651 Dongfeng Road East, Guangzhou 510060, Guangdong Province, PR China. ${ }^{5}$ Department of Critical Care Medicine, The Sixth Affiliated Hospital of Sun Yat-sen University, 26 Yuancun Erheng Rd, Guangzhou 510655, Guangdong Province, PR China. ${ }^{6}$ Department of Critical Care Medicine, The Second Affiliated Hospital of Sun Yat-sen University, 107 Yan-Jiang West Road, Guangzhou 510120, Guangdong Province, PR China. ${ }^{7}$ School of Public Health, Sun Yat-sen University, 74 Zhongshan Er Road, Guangzhou 510080, Guangdong Province, PR China.

Received: 7 August 2012 Revised: 18 October 2012

Accepted: 7 January 2013 Published: 17 January 2013

\section{References}

1. Heron M, Hoyert DL, Murphy SL, Xu J, Kochanek KD, Tejada-Vera B: Deaths: final data for 2006. Natl Vital Stat Rep 2009, 57:1-134.

2. Martin CM, Priestap F, Fisher H, Fowler RA, Heyland DK, Keenan SP, Longo CJ, Morrison T, Bentley D, Antman N, STAR Registry Investigators: A prospective, observational registry of patients with severe sepsis: the Canadian Sepsis Treatment and Response Registry. Crit Care Med 2009, 37:81-88.

3. Angus DC, Linde-Zwirble WT, Lidicker J, Clermont G, Carcillo J, Pinsky MR: Epidemiology of severe sepsis in the United States: analysis of incidence, outcome, and associated costs of care. Crit Care Med 2001, 29:1303-1310.

4. Levy MM, Dellinger RP, Townsend SR, Linde-Zwirble WT, Marshall JC, Bion J, Schorr C, Artigas A, Ramsay G, Beale R, Parker MM, Gerlach H, Reinhart K, Silva E, Harvey M, Regan S, Angus DC: The Surviving Sepsis Campaign: results of an international guideline-based performance improvement program targeting severe sepsis. Intensive Care Med 2010, 36:222-231.

5. Finfer S, Bellomo R, Lipman J, French C, Dobb G, Myburgh J: Adultpopulation incidence of severe sepsis in Australian and New Zealand intensive care units. Intensive Care Med 2004, 30:589-596.

6. Brun-Buisson C, Meshaka P, Pinton P, Vallet B, EPISEPSIS Study Group: EPISEPSIS: a reappraisal of the epidemiology and outcome of severe sepsis in French intensive care units. Intensive Care Med 2004, 30:580-588.

7. Bernard GR, Vincent JL, Laterre PF, LaRosa SP, Dhainaut JF, LopezRodriguez A, Steingrub JS, Garber GE, Helterbrand JD, Ely EW, Fisher CJ Jr, Recombinant human protein C Worldwide Evaluation in Severe Sepsis (PROWESS) study group: Efficacy and safety of recombinant human activated protein C for severe sepsis. N Engl J Med 2001, 344:699-709.

8. Hotchkiss RS, Karl IE: The pathophysiology and treatment of sepsis. N Engl J Med 2003, 348:138-150.

9. Hotchkiss RS, Opal S: Immunotherapy for sepsis - a new approach against an ancient foe. N Engl J Med 2010, 363:87-89.

10. Goldstein AL, Guha A, Zatz MM, Hardy MA, White A: Purification and biological activity of thymosin, a hormone of the thymus gland. Proc Natl Acad Sci USA 1972, 69:1800-1803.

11. Romani L, Bistoni F, Montagnoli C, Gaziano R, Bozza S, Bonifazi P, Zelante T, Moretti S, Rasi G, Garaci E, Puccetti P: Thymosin alpha1: an endogenous regulator of inflammation, immunity, and tolerance. Ann N Y Acad Sci 2007, 1112:326-338.

12. Goldstein AL: From lab to bedside: emerging clinical applications of thymosin alpha 1. Expert Opin Biol Ther 2009, 9:593-608.

13. Tuthill C, Rios I, McBeath R: Thymosin alpha 1: past clinical experience and future promise. Ann N Y Acad Sci 2010, 1194:130-135.

14. Chen H, He MY, Li YM: Treatment of patients with severe sepsis using ulinastatin and thymosin alpha1: a prospective, randomized, controlled pilot study. Chin Med J (Engl) 2009, 122:883-888. 
15. Li Y, Chen H, Li X, Zhou W, He M, Chiriva-Internati M, Wachtel MS, Frezza EE: A new immunomodulatory therapy for severe sepsis: Ulinastatin Plus Thymosin \{alpha\} 1. J Intensive Care Med 2009, 24:47-53.

16. Lin HY: [Clinical trial with a new immunomodulatory strategy: treatment of severe sepsis with Ulinastatin and Maipuxin]. Zhonghua Yi Xue Za Zhi 2007, 87:451-457.

17. Dellinger RP, Levy MM, Carlet JM, Bion J, Parker MM, Jaeschke R, Reinhart K, Angus DC, Brun-Buisson C, Beale R, Calandra T, Dhainaut JF, Gerlach H, Harvey M, Marini JJ, Marshall J, Ranieri M, Ramsay G, Sevransky J, Thompson BT, Townsend S, Vender JS, Zimmerman JL, Vincent JL, International Surviving Sepsis Campaign Guidelines Committee; American Association of Critical-Care Nurses; American College of Chest Physicians; American College of Emergency Physicians; Canadian Critical Care Society; European Society of Clinical Microbiology and Infectious Diseases, et al: Surviving Sepsis Campaign: international guidelines for management of severe sepsis and septic shock: 2008. Intensive Care Med 2008, 34:17-60.

18. Guidelines for the management of adults with hospital-acquired, ventilator-associated, and healthcare-associated pneumonia. Am J Respir Crit Care Med 2005, 171:388-416.

19. Degoricija V, Sharma M, Legac A, Gradiser M, Sefer S, Vucicevic Z: Survival analysis of 314 episodes of sepsis in medical intensive care unit in university hospital: impact of intensive care unit performance and antimicrobial therapy. Croat Med J 2006, 47:385-397.

20. Garnacho-Montero J, Garcia-Garmendia JL, Barrero-Almodovar A, JimenezJimenez FJ, Perez-Paredes C, Ortiz-Leyba C: Impact of adequate empirical antibiotic therapy on the outcome of patients admitted to the intensive care unit with sepsis. Crit Care Med 2003, 31:2742-2751.

21. Wu JF, Ma J, Chen J, Ou-Yang B, Chen MY, Li LF, Liu YJ, Lin AH, Guan XD: Changes of monocyte human leukocyte antigen-DR expression as a reliable predictor of mortality in severe sepsis. Crit Care 2011, 15:R220.

22. Huang SW, Guan XD, Chen J, OuYang B: [Clinical study and long-term evaluation of immunomodulation therapy on trauma, severe sepsis and multiple organ dysfunction syndrome patients]. Zhongguo Wei Zhong Bing Ji Jiu Yi Xue 2006, 18:653-656.

23. Remick DG: Pathophysiology of sepsis. Am J Pathol 2007, 170:1435-1444.

24. Abraham $E$, Wunderink $R$, Silverman $H$, Perl TM, Nasraway $S$, Levy $H$, Bone $R$, Wenzel RP, Balk R, Pennington JE, Wherry JC, TNF-alpha MAb Sepsis Study Group: Efficacy and safety of monoclonal antibody to human tumor necrosis factor alpha in patients with sepsis syndrome. A randomized, controlled, double-blind, multicenter clinical trial. JAMA 1995, 273:934-941.

25. Panacek EA, Marshall JC, Albertson TE, Johnson DH, Johnson S, MacArthur RD, Miller M, Barchuk WT, Fischkoff S, Kaul M, Teoh L, Van Meter L, Daum L, Lemeshow S, Hicklin G, Doig C, Monoclonal Anti-TNF: a Randomized Controlled Sepsis Study Investigators: Efficacy and safety of the monoclonal anti-tumor necrosis factor antibody $F\left(a b^{\prime}\right) 2$ fragment afelimomab in patients with severe sepsis and elevated interleukin- 6 levels. Crit Care Med 2004, 32:2173-2182.

26. Docke WD, Randow F, Syrbe U, Krausch D, Asadullah K, Reinke P, Volk HD, Kox W: Monocyte deactivation in septic patients: restoration by IFNgamma treatment. Nat Med 1997, 3:678-681.

27. Serrate SA, Schulof RS, Leondaridis L, Goldstein AL, Sztein MB: Modulation of human natural killer cell cytotoxic activity, lymphokine production, and interleukin 2 receptor expression by thymic hormones. J Immunol 1987, 139:2338-2343.

28. Sztein $M B$, Serrate $S A$ : Characterization of the immunoregulatory properties of thymosin alpha 1 on interleukin-2 production and interleukin-2 receptor expression in normal human lymphocytes. Int J Immunopharmacol 1989, 11:789-800.

29. Pierluigi B, D'Angelo C, Fallarino F, Moretti S, Zelante T, Bozza S, De Luca A, Bistoni F, Garaci E, Romani L: Thymosin alpha1: the regulator of regulators? Ann N Y Acad Sci 2010, 1194:1-5.

30. Romani L, Bistoni F, Gaziano R, Bozza S, Montagnoli C, Perruccio K, Pitzurra L, Bellocchio S, Velardi A, Rasi G, Di Francesco P, Garaci E: Thymosin alpha 1 activates dendritic cells for antifungal Th1 resistance through toll-like receptor signaling. Blood 2004, 103:4232-4239.

31. Bozza S, Gaziano R, Bonifazi P, Zelante T, Pitzurra L, Montagnoli C, Moretti S, Castronari R, Sinibaldi P, Rasi G, Garaci E, Bistoni F, Romani L: Thymosin alpha1 activates the TLR9/MyD88/IRF7-dependent murine cytomegalovirus sensing for induction of anti-viral responses in vivo. Int Immunol 2007, 19:1261-1270.
32. Yang X, Qian F, He HY, Liu KJ, Lan YZ, Ni B, Tian Y, Fu XL, Zhang J, Shen ZG, Li J, Yin Y, Li JT, Wu YZ: Effect of thymosin alpha-1 on subpopulations of Th1, Th2, Th17, and regulatory T cells (Tregs) in vitro. Braz J Med Biol Res 2012, 45:25-32.

33. Cheng B, Xie G, Yao S, Wu X, Guo Q, Gu M, Fang Q, Xu Q, Wang D, Jin Y, Yuan S, Wang J, Du Z, Sun Y, Fang X: Epidemiology of severe sepsis in critically ill surgical patients in ten university hospitals in China. Crit Care Med 2007, 35:2538-2546.

34. Schulz KF, Grimes DA: Allocation concealment in randomised trials: defending against deciphering. Lancet 2002, 359:614-618.

35. Monneret G, Venet F, Pachot A, Lepape A: Monitoring immune dysfunctions in the septic patient: a new skin for the old ceremony. Mol Med 2008, 14:64-78.

36. Schefold JC: Measurement of monocytic HLA-DR (mHLA-DR) expression in patients with severe sepsis and septic shock: assessment of immune organ failure. Intensive Care Med 2010, 36:1810-1812.

37. Lukaszewicz AC GM, Resche-Rigon M, Pirracchio R, Faivre V, Boval B, Payen D: Monocytic HLA-DR expression in intensive care patients: interest for prognosis and secondary infection prediction. Crit Care Med 2009, 37:2746-2752.

38. Monneret G, Lepape A, Voirin N, Bohe J, Venet F, Debard AL, Thizy H, Bienvenu J, Gueyffier F, Vanhems P: Persisting low monocyte human leukocyte antigen-DR expression predicts mortality in septic shock. Intensive Care Med 2006, 32:1175-1183.

39. Menges T, Engel J, Welters I, Wagner RM, Little S, Ruwoldt R, Wollbrueck M, Hempelmann G: Changes in blood lymphocyte populations after multiple trauma: association with posttraumatic complications. Crit Care Med 1999, 27:733-740.

40. Zhang Y, Chen H, Li YM, Zheng SS, Chen YG, Li LJ, Zhou L, Xie HY, Praseedom RK: Thymosin alpha1- and ulinastatin-based immunomodulatory strategy for sepsis arising from intra-abdominal infection due to carbapenem-resistant bacteria. J Infect Dis 2008, 198:723-730.

41. Wang X, Li W, Niu C, Pan L, Li N, Li J: Thymosin alpha 1 is associated with improved cellular immunity and reduced infection rate in severe acute pancreatitis patients in a double-blind randomized control study. Inflammation 2011, 34:198-202.

42. Saenz JJ, Izura JJ, Manrique A, Sala F, Gaminde I: Early prognosis in severe sepsis via analyzing the monocyte immunophenotype. Intensive Care Med 2001, 27:970-977.

43. Meisel C, Schefold JC, Pschowski R, Baumann T, Hetzger K, Gregor J, WeberCarstens S, Hasper D, Keh D, Zuckermann H, Reinke P, Volk HD: Granulocyte-macrophage colony-stimulating factor to reverse sepsisassociated immunosuppression: a double-blind, randomized, placebocontrolled multicenter trial. Am J Respir Crit Care Med 2009, 180:640-648.

44. Alberti C, Brun-Buisson C, Burchardi H, Martin C, Goodman S, Artigas A, Sicignano A, Palazzo M, Moreno R, Boulme R, Lepage E, Le Gall R: Epidemiology of sepsis and infection in ICU patients from an international multicentre cohort study. Intensive Care Med 2002, 28:108-121.

45. Ranieri VM, Thompson BT, Barie PS, Dhainaut JF, Douglas IS, Finfer S, Gardlund B, Marshall JC, Rhodes A, Artigas A, Payen D, Tenhunen J, AlKhalidi HR, Thompson V, Janes J, Macias WL, Vangerow B, Williams MD, PROWESS-SHOCK Study Group: Drotrecogin alfa (activated) in adults with septic shock. N Engl J Med 2012, 366:2055-2064.

46. Brunkhorst FM, Engel C, Bloos F, Meier-Hellmann A, Ragaller M, Weiler N, Moerer O, Gruendling M, Oppert M, Grond S, Olthoff D, Jaschinski U, John S, Rossaint R, Welte T, Schaefer M, Kern P, Kuhnt E, Kiehntopf M, Hartog C, Natanson C, Loeffler M, Reinhart K, German Competence Network Sepsis (SepNet): Intensive insulin therapy and pentastarch resuscitation in severe sepsis. N Engl J Med 2008, 358:125-139.

47. DeFronzo RA, Tripathy D, Schwenke DC, Banerji M, Bray GA, Buchanan TA, Clement SC, Henry RR, Hodis HN, Kitabchi AE, Mack WJ, Mudaliar S, Ratner RE, Williams K, Stentz FB, Musi N, Reaven PD, ACT NOW Study: Pioglitazone for diabetes prevention in impaired glucose tolerance. $\mathrm{N}$ Engl J Med 2011, 364:1104-1115.

48. TODAY Study Group, Zeitler P, Hirst K, Pyle L, Linder B, Copeland K, Arslanian S, Cuttler L, Nathan DM, Tollefsen S, Wilfley D, Kaufman F: A clinical trial to maintain glycemic control in youth with type 2 diabetes. N Engl J Med 2012, 366:2247-2256. 
doi:10.1186/cc11932

Cite this article as: Wu et al:: The efficacy of thymosin alpha 1 for severe sepsis (ETASS): a multicenter, single-blind, randomized and controlled trial. Critical Care 2013 17:R8.

Submit your next manuscript to BioMed Central and take full advantage of:

- Convenient online submission

- Thorough peer review

- No space constraints or color figure charges

- Immediate publication on acceptance

- Inclusion in PubMed, CAS, Scopus and Google Scholar

- Research which is freely available for redistribution 